\title{
RAZÃO DE PERDAS DE SOLO E FATOR C PARA MILHO E AVEIA EM ROTAÇÃO COM OUTRAS CULTURAS EM TRÊS TIPOS DE PREPARO DE SOLO ${ }^{(1)}$
}

\author{
I. BERTOL (2), J . SCHICK(3) \& O. BATISTELA(4)
}

\begin{abstract}
RESUMO
Dados de um experimento de perdas de solo e água sob chuva natural em Lages (SC), de novembro de 1992 a outubro de 1998, foram usados para o cálculo da razão de perdas de solo (RPS) e o fator $C$ da equação universal de perda de solo, em três sistemas de preparo com milho e aveia em rotação com outras culturas. Os tratamentos: aração + duas gradagens (A + G), escarificação + uma gradagem ( $E$ + G) e semeadura direta (SDI) foram submetidos ao cultivo de milho (Zea mays) e aveia preta (Avena sativa) em rotação com outras culturas e comparados à aração + duas gradagens sem culturas (SSC), sobre um Cambissolo Húmico alumínico com declividade média de $0,102 \mathrm{~m} \mathrm{~m}^{-1}$. O ciclo das culturas foi dividido em cinco estádios, com igual intervalo de duração. As RPS e os fatores C variaram amplamente entre os sistemas de preparo do solo e entre os estádios durante os ciclos das culturas, bem como entre os ciclos na mesma cultura e entre as culturas, indicando um forte efeito do manejo do solo, época do ano, cultura e chuva sobre essas variáveis. Os valores de RPS para o milho foram de 0,1189, 0,0888 e 0,0611 (Mg ha $\left.{ }^{-1}\right)\left(\mathrm{Mg} \mathrm{ha}^{-1}\right)^{-1}$, para a A + G, E + G e SDI, respectivamente, enquanto para a aveia esses valores foram, respectivamente, de 0,0783, 0,0655 e 0,0760 ( $\left.\mathrm{Mg} \mathrm{ha}^{-1}\right)\left(\mathrm{Mg} \mathrm{ha}^{-1}\right)^{-1}$. Para os mesmos sistemas de preparo do solo, os valores do fator $C$ foram, respectivamente, de 0,1097, 0,0809 e 0,0610 (Mg ha-1) (Mg ha-1)-1, para o milho, e de 0,0671, 0,0409 e 0,0372 (Mg ha $\left.{ }^{-1}\right)\left(\mathrm{Mg} \mathrm{ha}^{-1}\right)^{-1}$, para a aveia.
\end{abstract}

Termos de indexação: equação universal de perda de solo, erosão hídrica, preparo conservacionista.

\footnotetext{
(1) Parte da Tese de Mestrado do segundo autor. Desenvolvido com recursos da FINEP/UDESC/CAPES. Apresentado na V RELACO, Florianópolis, outubro, 1999. Recebido para publicação em julho de 2001 e aprovado em janeiro de 2002.

(2) Professor de Uso e Conservação do Solo, Universidade do Estado de Santa Catarina - CAV/UDESC. Av. Luiz de Camões 2090, Caixa Postal 281, CEP 88520-000 Lages (SC). Bolsista do CNPq. E-mail: a2ib@cav.udesc.br

(3) Engenheiro-Agronômo, MSc., CAV/UDESC.

(4) Engenheiro-Agronômo, CAV/UDESC.
} 


\begin{abstract}
SUMMARY: SOIL LOSS RATIO AND C FACTOR FOR CORN AND OAT IN ROTATION WITH OTHER CROPS IN THREE SOIL TILLAGE TYPES
\end{abstract}

\begin{abstract}
Soil and water loss data under natural rainfall in Lages, Santa Catarina State(Brazil), from N ovember 1992 to October 1998, wereutilized to cal culatethe soil loss ratio (SLR) and C factor for the Universal Soil Loss Equation (USLE) under three soil tillage systems for corn and oat in rotation with other crops. Thestudied treatments were pl owing fol lowed by disking twice $(P+D)$, chiseling plus disking $(C+D)$ and no-tillage $(N T) /$ direct sowing, cultivated with corn (Zea mays) and oat (Avena sativa) in rotation with other crops and compared to a check plot: plowing followed by double disking without crops (PDW), on an Inceptisol with an average slope of $0.102 \mathrm{~m} \mathrm{~m}^{-1}$. The culture cycle was divided in fivecrop stages with equal timeintervals. TheSLR and $C$ factors varied remarkably among thesoil tillage systems, crop cycl estages, cycl estages for samecrops, and between crops, indicating a strong effect of soil management, season, crop and rainfall on thesevariables. The SLR values for corn were $0.1189,0.0888$ and $0.0611\left(\mathrm{Mg} \mathrm{ha}^{-1}\right)\left(\mathrm{Mg} \mathrm{ha}^{-1}\right)^{-1}$ for the $\mathrm{P}+\mathrm{D}, \mathrm{C}+\mathrm{D}$ and NT soil tillage systems, respectively, while for oat the SLR values for the sametillage systems were $0.0783,0.0655$ and $0.0760\left(\mathrm{Mg} \mathrm{ha}^{-1}\right)\left(\mathrm{Mg} \mathrm{ha}^{-1}\right)^{-1}$. For the above mentioned soil tillage systems, the $C$ factors were $0.1097,0.0809$ and $0.0610\left(\mathrm{M} \mathrm{g} \mathrm{ha}^{-1}\right)\left(\mathrm{Mg} \mathrm{ha}^{-1}\right)^{-1}$ for corn and $0.0671,0.0409$ and $0.0372\left(\mathrm{Mg} \mathrm{ha}^{-1}\right)\left(\mathrm{Mg} \mathrm{ha}^{-1}\right)^{-1}$ for oat.
\end{abstract}

Index terms: universal soil loss equation, water erosion, conservation tillage.

\section{INTRODUÇÃO}

A predição da erosão hídrica e sua aplicação no planejamento de uso da terra são importantes, pois possibilitam comparar as perdas efetivas de sol ocom a tolerância de perda permitida para determinado solo, tanto do ponto de vista agrícola, quanto ambiental. Para isso, é necessário quantificar os fatores envolvidos na modelagem de erosão hídrica e, posteriormente, validar o referido modelo para cada local e condição edafoclimática.

A equação universal de perdas de solo (EUPS) é um model o empírico que possi bilita predizer a perda média anual de sol o por erosão hídrica, com base no conhecimento dos fatores locais que influenciam a erosão: erosividade da chuva e enxurrada a ela associada (fator R), susceptibilidade natural do solo à erosão (fator K), associação do comprimento da rampa epercentagem do declive (fator LS), cobertura emanejo do sol o (fator C) epráticas conservacionistas de suporte (fator P) (Wischmeier \& Smith, 1978).

O fator C da EUPS para uma cultura écal culado por meio do produto da razão de perda de solo (RPS) pela fração do índice de erosividade $\left(\mathrm{FEI}_{30}\right)$ do ciclo da cultura (Wischmeier \& Smith, 1978). A RPS expressa o quociente entre a perda de sol o ocorrida em determinado sistema de manejo eaquela ocorrida num solo sem cultura e descoberto, variando, portanto, de zero a um. A $\mathrm{FEI}_{30}$ também varia de zero a um, significando a percentagem do índice de erosividade que produziu a erosão utilizada no cálculo da respectiva RPS. Assim, ofator C da EUPS varia de zero a um, aproximando-se de zero, nos sistemas de manejo conservacionistas, e de um, nos sistemas não-conservacionistas.
O fator C varia de acordo com a variação da erosividadee erodi bilidade, para cada cultura etipos de manejo ou cultivo do solo. Portanto, há grande dificuldadena determinação desse fator, em virtude das muitas combinações possíveis de erosividade, cultura, sistema decultivo, tipo de preparo e manejo e tipo de solo.

Dechen et al. (1981) constataram que as gramíneas foram mais eficazes do que as leguminosas na diminuição das perdas de solo. Margolis et al. (1985) obtiveram menor fator C na semeadura direta do que nos demais sistemas de manejo e Dedecek et al. (1986) conduíram que a vegetação permanente, seguida da soja em semeadura direta, ocasionou menor RPS do que os demais sistemas de manejo.

Levien et al. (1990) concluíram que o primeiro mês após a semeadura éo mais crítico na cultura do milho, em relação à erosão hídrica, enquanto Hernani et al . (1997) constataram maior eficácia da semeadura direta, considerando os demais sistemas de manejo do solo, na redução da erosão hídrica, em todos os estádios de crescimento das culturas detrigo e soja.

DeMaria \& Lombardi Neto (1997) obtiveram valores defator $\mathrm{C}$ variando de 0,025 a 0,156 ( $\left.\mathrm{Mg} \mathrm{ha}^{-1}\right)$ $\left(\mathrm{Mg} \mathrm{ha}^{-1}\right)^{-1}$, para a cultura do milho, conforme as variações de solo, clima e manejo, enquanto Nascimento \& Lombardi Neto (1999) constataram que a mucuna-preta ocasionou menor RPS do quea crotalária elabelabe. Bertol et al. (2001), por outro lado, obtiveram val ores de fator $C$ variando de 0,0455 a 0,1437 e de 0,0588 a 0,2158, para a sucessão soja e trigo, respectivamente, dependendo do sistema de manejo do solo. 
O objetivo deste trabal ho foi calcular a RPS e o fator $C$ para as culturas de milhoe aveia em rotação com outras culturas, em condições de chuva natural, para os sistemas de preparo do solo aração + duas gradagens, escarificação + uma gradagem e semeadura direta, em um Cambissolo Húmico alumínico, visando à sua utilização na EUPS para a predição da perda de solo na região de Lages (SC).

\section{MATERIAL E MÉTODOS}

O experimento foi realizado entre novembro de 1992 e outubro de 1998, no Campus do Centro de Ciências Agroveterinárias de Lages (SC), situado a 27은 $9^{\prime}$ de latitude sul e 50을 de longitude oeste, com 937 m de altitude média, na região do Planalto Sul Catarinense, onde o clima é do tipo Cfb, segundo a classificação de Köeppen. O solo no local do experimento é um Cambissolo Húmico alumínico argiloso horizonte $\mathrm{A}$ moderado, com substrato composto de siltitos + argilitos e declividade média de 0,102 $\mathrm{m} \mathrm{m}^{-1}$, descrito em Bertol (1994).

Os tratamentos de preparo do solo, executados duas vezes ao ano sem repetição, consistiram em: uma aração+duas gradagens $(A+G)$; uma escarificação +uma gradagem $(E+G)$, esemeadura direta (SDI ). Além desses, um tratamento com uma aração + duas gradagens, em duas repetições, foi mantido sem cultura elivre de vegetação e de crosta superficial (SSC) (parcela-padrão da EUPS). Foram estudados o milho (Zea mays) e a aveia preta (Avena sativa), em rotação com outras culturas.

O milho foi semeado em linhas espaçadas de $0,90 \mathrm{~m}$, paralel as ao dedive, com semeadora manual ("saraquá"), tendo recebido, em média, $140 \mathrm{~kg} \mathrm{ha}^{-1}$ cultivo-1 de superfosfato tripl o e $150 \mathrm{~kg} \mathrm{ha}^{-1}$ cultivo-1 $^{-1}$ declor eto de potássio, respectivamente. A massa seca produzida foi de $10,0 \mathrm{Mg} \mathrm{ha}^{-1}$ cultivo-1 $^{-1}$. A aveia preta foi semeada a lanço, sem adubo, com $150 \mathrm{~kg} \mathrm{ha}^{-1}$ de sementes, tendo produzido $8,0 \mathrm{Mg} \mathrm{ha}^{-1} \mathrm{cultivo}^{-1}$ de massa seca.

A unidade experimental constituiu-se de uma parcela com 22,1 x 3,5 m, delimitada lateralmente e na extremidadesuperior por chapas galvanizadas cravadas $10 \mathrm{~cm}$ no solo e, na extremidade inferior, por um sistema coletor de enxurrada composto de uma calha para receber o material erodido, conectada por um tubo de PVC a um primeirotanque situado seis metros abaixo da parcela, com capacidade de $750 \mathrm{~L}$. Este, por sua vez, estava ligado, por meio de um divisor de enxurrada com nove janelas, a um segundo tanque, também com capacidade de $750 \mathrm{~L}$.

A coleta e o processamento das amostras de enxurrada para a quantificação das per das de sol oe água foram feitos seguindo o método proposto por
Cogo (1978). As perdas de solo observadas no campo foram ajustadas para o declive de $0,09 \mathrm{~m} \mathrm{~m}^{-1}$ (parcela-padrão da EUPS), seguindo o procedimento deWischmeier \& Smith (1978).

Para o cál culo da erosividade $\left(\mathrm{EI}_{30}\right)$, estudaramse chuvas erosivas individuais, conceituadas por Wischmeier (1959) e Wischmeier \& Smith (1978), para as quais, após terem si do cotadas em segmentos de intensidade uniforme, calculou-se a energia cinética por meio de programa computacional (Cataneo et al., 1982), seguindo-seo método proposto por Wischmeier \& Smith (1978), expressando o resultado em unidades métricas, conforme sugerido por Foster et al. (1981).

Para obter o fator $\mathrm{C}$, os estádios durante o ciclo das culturas devem ser estabel ecidos considerandose a percentagem de cobertura do solo ocasionada por elas (Wischmeier \& Smith, 1978). Neste experimento, no entanto, não foram feitas as determinações da cobertura pela copa das plantas. Assim, para estabelecer os referidos estádi os, adotouse um procedimento semel hante ao de Wischmeier (1960), ou seja, o ciclo de cada cultura foi dividido em cinco estádios, com igual tempo de duração em cada um deles.

A RPS em cada estádio do ciclo das culturas foi calculada pelo quociente entre a perda de solo ocorrida no tratamento com determinada cultura e a ocorrida na parcela-padrão da EUPS. A FEI 30 , em cada estádio do ciclo das culturas, foi obtida pelo quociente entre o valor da erosividade, $\mathrm{EI}_{30}$, que causou a perda de solo em cada um dos estádios no cid o das culturas, e o val or total da erosividade, $\mathrm{EI}_{30}$, ocorrida no ciclo das referidas culturas. O fator $\mathrm{C}$, para cada estádio durante o ciclo das culturas, foi calculado pelo produto da RPS e $\mathrm{FEI}_{30}$ do referido estádio. O somatório dos valores do fator $\mathrm{C}$ dos estádios do cid o das culturas permitiu obter ofator $C$ das referidas culturas.

\section{RESULTADOS E DISCUSSÃO}

$\mathrm{Na}$ média dos tratamentos de preparo do solo envolvendo culturas, houve redução na erosão hídrica em $95 \%$, para a cultura do milho, eem $93 \%$, para a cultura da aveia, em relação ao SSC (Quadro 1). No caso da SDI, a referida redução foi de $96 \%$, tanto no milho quanto na aveia, enquanto na $\mathrm{E}+\mathrm{G}$ eA + G, ela foi de 94 e $94 \%$, respectivamente, no milho, e respectivamente, de 94 e $88 \%$, na aveia, cujos dados são semel hantes aos obtidos por Bertol et al. (2001). Tal comportamento é explicado pelo efeito dos resíduos vegetais da parte aérea que protegeram a superfície do solo contra os agentes erosivos e pelo efeito das raízes que provavel mente melhoraram a estrutura do solo, aumentando sua resistência à erosão hídrica. 
Quadro 1. Valores médios de perdas de solo ajustadas para a declividade média de $0,09 \mathrm{~m} \mathrm{~m}^{-1}$ e erosi vidade das chuvas, durante 0 ciclo das culturas, em diferentes preparos em um Cambissolo Húmico alumínico em Lages (SC) (média de dois cultivos)

\begin{tabular}{ccc}
\hline Tratamento & Milho(1) & Aveia(2) \\
\hline & \multicolumn{2}{c}{ Mg ha-1 $^{-1}$ cultivo-1 $^{-1}$} \\
SSC & 57,33 & 41,50 \\
A + G & 3,42 & 4,91 \\
E + G & 3,35 & 2,53 \\
SDI & 2,10 & 1,67
\end{tabular}

SSC: solo sem cultura (parcela-padrão da EUPS); A + G: aração + duas gradagens; $\mathrm{E}+\mathrm{G}$ : escarificação+uma gradagem; SDI: semeadura direta. ${ }^{(1)}\left(\mathrm{EI}_{30}=3.106 \mathrm{MJ} \mathrm{mm} \mathrm{ha}^{-1} \mathrm{~h}^{-1}\right.$ cultivo-1 $\left.^{-1}\right)$ ${ }^{(2)} \mathrm{EI}_{30}=2.390 \mathrm{MJ} \mathrm{mm} \mathrm{ha-1} \mathrm{h}^{-1}$ cultivo ${ }^{-1}$.

As perdas de solo nos tratamentos com culturas foram relativamente baixas, independentemente do sistema de preparo e do tipo de cultura (Quadro 1), comparadas à tolerância de perda para esse solo determinada por Bertol \& Almeida (2000), concordando com Bertol (1994), Schick et al. (2000) e Bertol et al. (2001). I sto é explicado pelo fato de grandes quantidades de resíduos culturais, especialmente de milho, trigo e aveia, terem sido incorporadas no solo no tratamento $A+G$, semiincorporadas na $E+G$ e mantidas na superfície na SDI (Schick et al., 2000), o que provavelmente contribuiu para aumentar a resistência do solo à erosão nesses tratamentos. Além disso, a rugosidade superficial, ocasionada pel o preparo do sol ona $A+G$ ena $E+G$, foi alta (Schick et al., 2000), enquanto os valores médios anuais de erosividade foram relativamente baixos (Quadro 1).

A cultura da aveia reduziu as perdas de solo em $34 \%$ em relação à cultura do milho, na média dos sistemas de preparo do solo, com a maior redução na $\mathrm{E}+\mathrm{G}(24 \%)$ (Quadro 1). I Isto é explicado pelas características das culturas, sendo mai or a densi dade radicular da aveia do que do milho, o que provavelmente aumentou a resistência do solo à erosão na aveia em relação ao milho. Além disso, a erosividade média anual foi cerca de $23 \%$ menor no outono-inverno (época de cultivo da aveia) do que na primavera-verão (época de cultivo do milho) (Quadro 1), embora os volumes de precipitação tenham sido praticamente iguais em ambos os ciclos de cultivo (Quadro 2).

A erosividade das chuvas apresentou grande variação de distribuição entre os estádios, ciclos e culturas (Quadros 3e 4), concordando com dados de Margolis et al. (1985), Dedecek et al. (1986), DeMaria \& Lombardi Neto (1997), Nascimento \& Lombardi Neto (1999) e Bertol et al. (2001). Essa variação na distribuição temporal da erosividade das chuvas é normal, em conseqüência da variação climática, indicando a necessidade da continuidade de pesquisas dessa natureza por um período de tempo mais longo (Wischmeier \& Smith, 1978).

As perdas de solo no SSC, do mesmo modo como a erosividade, variaram entre os estádios, ciclos e culturas (Quadros 3 e 4), concordando com dados de Margolis et al . (1985), Dedecek et al. (1986), De Maria \& Lombardi Neto (1997), N ascimento \& Lombardi Neto (1999) e Bertol et al. (2001). NoSSC, a variação de perda de solo entre os estádios foi maior do que no caso da erosividade, concordando com dados DeMaria \& Lombardi Neto (1997) e Bertol et al. (2001). Essa maior variação nas perdas de solo do que nas erosividades, nesse tratamento, é explicada pela provável variabilidade da umidade antecedente do sol o no momento de ocorrência das chuvas.

Durante o cid o do milho (Quadro 3), em geral, não houve uma correspondência entre as erosividades e as perdas de sol o noSSC, ou seja, em poucas ocasiões uma alta erosividade proporcionou uma alta perda de sol o e uma baixa erosividade proporcionou uma baixa perda de solo. Isto se explica pela provável variabilidade na umidade antecedente do solo durante os ciclos dessa cultura (primavera-verão), fato comum no sul do Brasil. Duranteo cido da aveia (Quadro 4), no entanto, houve uma melhor correspondência entre erosividades e perdas de solo noSSC, explicado da mesma forma como no caso da soja, ou seja, a umidade do solo foi provavelmente

Quadro 2. Valores de $\mathrm{EI}_{30}$ e volumes de chuvas ocorridos durante os ciclos das culturas de milho e aveia em Lages (SC)

\begin{tabular}{|c|c|c|c|c|c|}
\hline \multicolumn{3}{|c|}{ Cultura de milho } & \multicolumn{3}{|c|}{ Cultura de aveia } \\
\hline Ciclo da cultura & $E_{1} 30$ & Volume & Ciclo da cultura & E I 30 & Volume \\
\hline Data & MJ mm ha-1 $\mathrm{h}^{-1}$ & $\mathrm{~mm}$ & Data & MJ mm ha-1 h-1 & $\mathrm{mm}$ \\
\hline $\begin{array}{l}19 / 11 / 94 \text { a } 30 / 07 / 95 \\
16 / 11 / 97 \text { a } 30 / 04 / 98\end{array}$ & $\begin{array}{l}1.469 \\
4.742\end{array}$ & $\begin{array}{r}554 \\
1.035\end{array}$ & $\begin{array}{l}09 / 06 / 93 \text { a } 17 / 11 / 93 \\
01 / 05 / 98 \text { a } 30 / 10 / 98\end{array}$ & $\begin{array}{l}2.659 \\
2.120\end{array}$ & $\begin{array}{l}663 \\
895\end{array}$ \\
\hline Total & 6.211 & 1.589 & Total & 4.779 & 1.558 \\
\hline Média & 3.106 & 795 & Média & 2.390 & 779 \\
\hline
\end{tabular}


Quadro 3. Valores de perdas de solo no solo sem cultura ajustados para a declividade média de 0,09 $\mathrm{m} \mathrm{m}^{-1}$, fração do $\mathrm{El}_{30}$, razão de perdas de solo e fator $\mathrm{C}$ em diferentes estádios nos ciclos culturais do milho, em três sistemas de manejo do Cambissolo Húmico alumínico em Lages (SC)

\begin{tabular}{|c|c|c|c|c|c|c|c|c|c|}
\hline \multirow{2}{*}{$\begin{array}{c}\text { Ciclo } \\
\text { da } \\
\text { cultura }\end{array}$} & \multirow{2}{*}{$\begin{array}{c}\text { E stádio } \\
\text { no ciclo } \\
\text { da cultura }\end{array}$} & \multirow{2}{*}{ ssc } & \multirow{2}{*}{ FE I $_{30}$} & \multicolumn{2}{|c|}{$A+G$} & \multicolumn{2}{|c|}{$\mathbf{E}+\mathbf{G}$} & \multicolumn{2}{|c|}{ SDI } \\
\hline & & & & RPS & C & RPS & C & RPS & C \\
\hline & & $\mathrm{kg} \mathrm{ha}^{-1}$ & & & & & & & \\
\hline $\begin{array}{c}19 / 11 / 94 \\
a \\
30 / 07 / 95\end{array}$ & $\begin{array}{l}1^{(1)} \\
2^{(1)} \\
3^{(1)} \\
4^{(1)} \\
5^{(1)}\end{array}$ & $\begin{array}{r}1.559,08 \\
1.162,21 \\
33,96 \\
60,17 \\
4,35\end{array}$ & $\begin{array}{l}0,1342 \\
0,5684 \\
0,0612 \\
0,0908 \\
0,1454\end{array}$ & $\begin{array}{l}0,0886 \\
0,1443 \\
0,0710 \\
0,4266 \\
0,2736\end{array}$ & $\begin{array}{l}0,0119 \\
0,0820 \\
0,0043 \\
0,0387 \\
0,0398\end{array}$ & $\begin{array}{l}0,3061 \\
0,0866 \\
0,0968 \\
0,1557 \\
0,0966\end{array}$ & $\begin{array}{l}0,0411 \\
0,0492 \\
0,0059 \\
0,0141 \\
0,0140\end{array}$ & $\begin{array}{l}0,0639 \\
0,0966 \\
0,1293 \\
0,1428 \\
0,0920\end{array}$ & $\begin{array}{l}0,0086 \\
0,0549 \\
0,0079 \\
0,0130 \\
0,0134\end{array}$ \\
\hline & Média & 563,95 & 0,2000 & 0,2008 & 0,0353 & 0,1484 & 0,0249 & 0,1049 & 0,0196 \\
\hline $\begin{array}{c}16 / 11 / 97 \\
a \\
30 / 04 / 98\end{array}$ & $\begin{array}{l}1^{(2)} \\
2^{(2)} \\
3^{(2)} \\
4^{(2)} \\
5^{(2)}\end{array}$ & $\begin{array}{r}3.703,84 \\
1.008,13 \\
26.592,71 \\
22.663,63 \\
57.853,59\end{array}$ & $\begin{array}{l}0,0782 \\
0,0688 \\
0,2799 \\
0,2451 \\
0,3280\end{array}$ & $\begin{array}{l}0,0517 \\
0,0168 \\
0,0060 \\
0,0078 \\
0,1029\end{array}$ & $\begin{array}{l}0,0040 \\
0,0012 \\
0,0017 \\
0,0019 \\
0,0338\end{array}$ & $\begin{array}{l}0,0225 \\
0,0177 \\
0,0010 \\
0,0028 \\
0,1021\end{array}$ & $\begin{array}{l}0,0018 \\
0,0012 \\
0,0003 \\
0,0007 \\
0,0335\end{array}$ & $\begin{array}{l}0,0138 \\
0,0020 \\
0,0020 \\
0,0028 \\
0,0657\end{array}$ & $\begin{array}{l}0,0011 \\
0,0001 \\
0,0006 \\
0,0007 \\
0,0216\end{array}$ \\
\hline & Média & $22.364,39$ & 0,2000 & 0,0370 & 0,0085 & 0,0292 & 0,0075 & 0,0173 & 0,0048 \\
\hline $\begin{array}{l}\text { Média de } \\
\text { dois ciclos }\end{array}$ & & $11.464,17$ & 0,2000 & 0,1189 & 0,0219 & 0,0888 & 0,0162 & 0,0611 & 0,0122 \\
\hline C.V. (\%) & & 158 & 76 & 107 & 115 & 99 & 108 & 84 & 129 \\
\hline
\end{tabular}

SSC: solo sem cultura; $\mathrm{FEI}_{30}$ : fração do índice de erosividade, $\mathrm{EI}_{30}$, no estádio da cultura; $\mathrm{A}+\mathrm{G}$ : aração + duas gradagens; $\mathrm{E}+\mathrm{G}$ : escarificação + uma gradagem; SDI: semeadura direta; RPS: razão de perdas de solo entre um tratamento qualquer e o solo sem cultura, $\left(\mathrm{Mg} \mathrm{ha}^{-1}\right)\left(\mathrm{Mg} \mathrm{ha}^{-1}\right)^{-1}$; C: fator $\mathrm{C}=$ produto da RPS pela $\mathrm{FEI}_{30}$. CV: coeficiente de variação. ${ }^{\text {(1) }} 50$ dias por estádio. (2) 39 dias por estádio.

Quadro 4. Valores de perdas de solo no solo sem cultura ajustados para a declividade média de 0,09 $\mathrm{m} \mathrm{m}^{-1}$, fração do $\mathrm{EI}_{30}$, razão de perdas de solo e fator $\mathrm{C}$ em diferentes estádios nos ciclos culturais da aveia, em três sistemas de manejo do Cambissolo Húmico alumínico em Lages (SC)

\begin{tabular}{|c|c|c|c|c|c|c|c|c|c|}
\hline \multirow{2}{*}{$\begin{array}{c}\text { Ciclo } \\
\text { da } \\
\text { cultura }\end{array}$} & \multirow{2}{*}{$\begin{array}{c}\text { Estádio } \\
\text { no ciclo } \\
\text { da cultura }\end{array}$} & \multirow{2}{*}{ sSC } & \multirow{2}{*}{ FEI 30} & \multicolumn{2}{|c|}{$\mathbf{A}+\mathbf{G}$} & \multicolumn{2}{|c|}{$\mathbf{E}+\mathbf{G}$} & \multicolumn{2}{|c|}{ SDI } \\
\hline & & & & RPS & C & RPS & C & RPS & C \\
\hline & & $\mathrm{kg} \mathrm{ha}^{-1}$ & & & & & & & \\
\hline $\begin{array}{c}09 / 06 / 93 \\
a \\
17 / 11 / 93\end{array}$ & $\begin{array}{l}1^{(1)} \\
2^{(1)} \\
3^{(1)} \\
4^{(1)} \\
5^{(1)}\end{array}$ & $\begin{array}{r}56.067,24 \\
19,66 \\
70,69 \\
180,45 \\
249,35\end{array}$ & $\begin{array}{l}0,5163 \\
0,0180 \\
0,0840 \\
0,1170 \\
0,2647\end{array}$ & $\begin{array}{l}0,0531 \\
0,1343 \\
0,1275 \\
0,0875 \\
0,0136\end{array}$ & $\begin{array}{l}0,0274 \\
0,0024 \\
0,0107 \\
0,0102 \\
0,0036\end{array}$ & $\begin{array}{l}0,0260 \\
0,2482 \\
0,0719 \\
0,1460 \\
0,0267\end{array}$ & $\begin{array}{l}0,0134 \\
0,0045 \\
0,0061 \\
0,0171 \\
0,0071\end{array}$ & $\begin{array}{l}0,0146 \\
0,4181 \\
0,0621 \\
0,0345 \\
0,0088\end{array}$ & $\begin{array}{l}0,0075 \\
0,0073 \\
0,0052 \\
0,0040 \\
0,0023\end{array}$ \\
\hline & Média & $11.317,48$ & 0,2000 & 0,0832 & 0,0109 & 0,1038 & 0,0096 & 0,1076 & 0,0053 \\
\hline $\begin{array}{c}01 / 05 / 98 \\
a \\
30 / 10 / 98\end{array}$ & $\begin{array}{l}1^{(2)} \\
2^{(2)} \\
3^{(2)} \\
4^{(2)} \\
5^{(2)}\end{array}$ & $\begin{array}{r}3.929,00 \\
4.140,89 \\
3.805,20 \\
11.671,78 \\
2.853,37\end{array}$ & $\begin{array}{l}0,1093 \\
0,0801 \\
0,1488 \\
0,4170 \\
0,2448\end{array}$ & $\begin{array}{l}0,0237 \\
0,1109 \\
0,0804 \\
0,1109 \\
0,0411\end{array}$ & $\begin{array}{l}0,0026 \\
0,0089 \\
0,0120 \\
0,0462 \\
0,0101\end{array}$ & $\begin{array}{l}0,0257 \\
0,0117 \\
0,0310 \\
0,0519 \\
0,0150\end{array}$ & $\begin{array}{l}0,0028 \\
0,0009 \\
0,0046 \\
0,0216 \\
0,0037\end{array}$ & $\begin{array}{l}0,0478 \\
0,0301 \\
0,0274 \\
0,0448 \\
0,0719\end{array}$ & $\begin{array}{l}0,0052 \\
0,0024 \\
0,0041 \\
0,0187 \\
0,0176\end{array}$ \\
\hline & Média & $5.280,05$ & 0,2000 & 0,0734 & 0,0160 & 0,0271 & 0,0067 & 0,0444 & 0,0096 \\
\hline $\begin{array}{l}\text { Média de } \\
\text { dois ciclos }\end{array}$ & & $8.298,77$ & 0,2000 & 0,0783 & 0,0134 & 0,0655 & 0,0082 & 0,0760 & 0,0074 \\
\hline C.V. (\%) & & 196 & 76 & 53 & 96 & 109 & 79 & 152 & 76 \\
\hline
\end{tabular}

SSC: solo sem cultura; $\mathrm{FEI}_{30}$ : fração do índice de erosividade, $\mathrm{EI}_{30}$, no estádio da cultura; $\mathrm{A}+\mathrm{G}$ : aração + duas gradagens; $\mathrm{E}+\mathrm{G}$ : escarificação + uma gradagem; SDI: semeadura direta; RPS: razão de perdas de solo entre um tratamento qualquer e o solo sem cultura, $\left(\mathrm{Mg} \mathrm{ha}^{-1}\right)\left(\mathrm{Mg} \mathrm{ha}^{-1}\right)^{-1}$; $\mathrm{C}$ : fator $\mathrm{C}=$ produto da RPS pela $\mathrm{FEI}_{30}$; CV: coeficiente de variação. (1) 32 dias por estádio. (2) 36 dias por estádio. 
maior e menos variável no outono-inverno, o que também é comum no sul do Brasil.

Os valores deRPS foram distintos entreos estádios, cid os e culturas, nos três sistemas de preparo do solo, embora a erosividade tenha sido semelhante em várias dessas situações (Quadros 3 e4), concordando com dados obtidos por DeMaria \& Lombardi Neto (1997) eBertol et al. (2001). Por exemplo, no estádio 4 da cultura de milho, no ciclo de 19/11/94 a 30/07/ 95 (Quadro 3), a erosividade foi equival ente a 9,1\% doEI 30 total do ciclo, enquanto a RPS no tratamento A +G, nesse estádio, a 42,7 \% daquela ocorrida noSSC. Noestádio 3, no entanto, a erosividadefoi equival ente a $6,1 \%$ do $\mathrm{EI}_{30}$ total ea RPS a 7,1 \% daquel a ocorrida no SSC. Comportamentos semel hantes ocorreram também na cultura da aveia (Quadro 4), cujos dados concordam com aqueles obtidos por Dedecek et al. (1986), DeMaria \& Lombardi N eto (1997) e Bertol et al. (2001). I sto é explicado pelo fato de serem as perdas de sol o fortemente influenciadas não só pela cobertura do sol o ocasionada pela copa das plantas, a qual aumenta com o seu crescimento, mas também pelo efeito positivo das raízes na agregação do solo. Além disso, tanto nos tratamentos com culturas (SDI , $\mathrm{E}+\mathrm{G}$ eA $+\mathrm{G}$ ) quanto naquel e sem cultura (SSC), a erosão depende da umidadeantecedente do solo, bem como das condições da superfície do sol o (cobertura com invasoras e resíduos culturais e rugosidade superficial ocasionada por capinas mecânicas) no momento de ocorrência das chuvas.

As RPS variaram com osistema de preparo do solo, tanto para o milho (Quadro 3) quanto para a aveia (Quadro 4), concordando com Dedecek et al. (1986), DeMaria \& Lombardi Neto (1997) e Bertol et al. (2001). Na média dos ciclos culturais, a SDI reduziu as RPS em 49 e $31 \%$ em relação a $A+G$ e $E+G$, respectivamente, na cultura de milho (Quadro 3), enquanto na aveia (Quadro 4), essa redução foi de $3 \%$ em relação a $A+G$ e, em relação à $E+G$, houve aumento de $16 \%$. I sto significa que, em relação ao $A+G$, a SDI perdeu uma quantidade de solo equivalente a 51 e $97 \%$ daquela perdida na $A+G$, nas culturas de milho e aveia, respectivamente, enquanto as respectivas perdas, equivalentes à $\mathrm{E}+\mathrm{G}$, foram de 69 e $116 \%$, o que, mais uma vez, ressal ta a importância da SDI no controle das perdas de solo, na maioria das situações.

Espera-se que tanto os valores de RPS quanto os de fator $C$ diminuam à medida que a cultura se desenvolva, aumentando a cobertura e mel horando a estrutura do solo. Os dados de RPS e fator C, constantes nos quadros 3, 4 e 5, não mostram

Quadro 5. Valores médios de perdas de solo no solo sem cultura ajustados para a declividade média de $0,09 \mathrm{~m} \mathrm{~m}^{-1}$, fração do $\mathrm{EI}_{30}$, razão de perdas de solo e fator $\mathrm{C}$ para as culturas de mil ho e aveia, em três sistemas de manejo do Cambissolo Húmico alumínico em Lages (SC) (média de dois cultivos)

\begin{tabular}{|c|c|c|c|c|c|c|c|c|c|}
\hline \multirow{2}{*}{$\begin{array}{c}\text { É poca } \\
\text { de } \\
\text { cultivo }\end{array}$} & \multirow{2}{*}{$\begin{array}{c}\text { E stádio } \\
\text { no ciclo } \\
\text { da cultura }\end{array}$} & \multirow{2}{*}{ SSC } & \multirow{2}{*}{ FE I 30} & \multicolumn{2}{|c|}{$\mathbf{A}+\mathbf{G}$} & \multicolumn{2}{|c|}{$\mathbf{E}+\mathbf{G}$} & \multicolumn{2}{|c|}{ SDI } \\
\hline & & & & RPS & C & RPS & C & RPS & C \\
\hline & & $\mathrm{kg} \mathrm{ha}^{-1}$ & & & & & & & \\
\hline \multicolumn{10}{|c|}{ Cultura de milho } \\
\hline \multirow[t]{4}{*}{$\begin{array}{l}\text { Primavera } \\
\text { verão }\end{array}$} & $\begin{array}{l}1^{(1)} \\
2^{(1)} \\
3^{(1)} \\
4^{(1)} \\
5^{(1)}\end{array}$ & $\begin{array}{r}2.531,46 \\
1.085,17 \\
13.313,34 \\
11.361,90 \\
28.928,97\end{array}$ & $\begin{array}{l}0,1062 \\
0,3186 \\
0,1706 \\
0,1679 \\
0,2367\end{array}$ & $\begin{array}{l}0,0702 \\
0,0806 \\
0,0385 \\
0,2172 \\
0,1883\end{array}$ & $\begin{array}{l}0,0080 \\
0,0416 \\
0,0030 \\
0,0203 \\
0,0368\end{array}$ & $\begin{array}{l}0,1643 \\
0,0522 \\
0,0489 \\
0,0792 \\
0,0994\end{array}$ & $\begin{array}{l}0,0214 \\
0,0252 \\
0,0031 \\
0,0074 \\
0,0238\end{array}$ & $\begin{array}{l}0,0388 \\
0,0493 \\
0,0656 \\
0,0728 \\
0,0789\end{array}$ & $\begin{array}{l}0,0048 \\
0,0275 \\
0,0044 \\
0,0068 \\
0,0175\end{array}$ \\
\hline & Média & $11.464,17$ & 0,2000 & 0,1189 & 0,0219 & 0,0888 & 0,0162 & 0,0611 & 0,0122 \\
\hline & C.V. (\%) & 87 & 36 & 59 & 70 & 47 & 56 & 24 & 74 \\
\hline & Total & $57.320,84$ & 1,0000 & $0,1189^{(3)}$ & 0,1097 & $0,0888^{(3)}$ & 0,0809 & $0,0611^{(3)}$ & 0,0610 \\
\hline \multicolumn{10}{|c|}{ Cultura de aveia } \\
\hline \multirow[t]{4}{*}{$\begin{array}{l}\text { Outono } \\
\text { inverno }\end{array}$} & $\begin{array}{l}1^{(2)} \\
2^{(2)} \\
3^{(2)} \\
4^{(2)} \\
5^{(2)}\end{array}$ & $\begin{array}{r}29.998,12 \\
2.080,28 \\
1.937,95 \\
5.926,17 \\
1.551,36\end{array}$ & $\begin{array}{l}0,3128 \\
0,0491 \\
0,1164 \\
0,2670 \\
0,2547\end{array}$ & $\begin{array}{l}0,0384 \\
0,1226 \\
0,1040 \\
0,0992 \\
0,0274\end{array}$ & $\begin{array}{l}0,0150 \\
0,0057 \\
0,0114 \\
0,0281 \\
0,0069\end{array}$ & $\begin{array}{l}0,0259 \\
0,1299 \\
0,0515 \\
0,0991 \\
0,0208\end{array}$ & $\begin{array}{l}0,0081 \\
0,0027 \\
0,0054 \\
0,0193 \\
0,0054\end{array}$ & $\begin{array}{l}0,0312 \\
0,2241 \\
0,0447 \\
0,0397 \\
0,0403\end{array}$ & $\begin{array}{l}0,0065 \\
0,0048 \\
0,0046 \\
0,0114 \\
0,0099\end{array}$ \\
\hline & Média & $8.298,77$ & 0,2000 & 0,0783 & 0,0134 & 0,0655 & 0,0082 & 0,0760 & 0,0074 \\
\hline & C.V. (\%) & 132 & 50 & 49 & 60 & 65 & 71 & 98 & 37 \\
\hline & Total & $41.493,82$ & 1,0000 & $0,0783^{(3)}$ & 0,0671 & $0,0655^{(3)}$ & 0,0409 & $0,0760^{(3)}$ & 0,0372 \\
\hline
\end{tabular}

SSC: solo sem cultura; $\mathrm{FEI}_{30}$ : fração do índice de erosividade, $\mathrm{EI}_{30}$, no estádio da cultura; A + G: aração + duas gradagens; $\mathrm{E}+\mathrm{G}$ : escarificação + uma gradagem; SDI : semeadura direta; RPS: razão de perdas de solo entre um tratamento qualquer e o solo sem cultura, $\left(\mathrm{Mg} \mathrm{ha}^{-1}\right)\left(\mathrm{Mg} \mathrm{ha}^{-1}\right)^{-1}$; $\mathrm{C}$ : fator $\mathrm{C}=$ produto da RPS pela $\mathrm{FEI}_{30} ;{ }^{(1)} \mathrm{Em}$ média, 45 dias por estádio. ${ }^{(2)} \mathrm{Em}$ média, 34 dias por estádio. (3) Média dos valores dos estádios durante o ciclo da cultura. CV: coeficiente de variação. 
tendência clara quanto a esse aspecto, discordando de outros trabal hos (Levien et al., 1990; DeMaria \& Lombardi N eto, 1997), nos quais se constatou que o estádio crítico de perda de solo em geral foi aquele que sucedeu à semeadura. I sto é explicado pel o fato de que os estádios dos ciclos das culturas foram definidos, dividindo-se os cidos em cinco estádios com igual duração de tempo entre eles. Portanto, não se consideraram os intervalos de tempo entre o preparo primário esecundário do solo, bem como os intervalos necessários para que as culturas atingissem determinado estádio de crescimento e de proteção do solo, ou, ainda, aqueles após as colheitas, como o fizeram os autores supramencionados.

Os valores de fator $C$ para a cultura de milho (Quadros 3 e 6) foram de 0,1097, 0,0809 e 0,0610 $\left(\mathrm{Mg} \mathrm{ha}^{-1}\right)\left(\mathrm{Mg} \mathrm{ha}^{-1}\right)^{-1}$, para a $\mathrm{A}+\mathrm{G}, \mathrm{E}+\mathrm{G}$ e SDI, respectivamente, enquanto para a cultura de aveia (Quadros 4 e 6), os referidos valores, para os respectivos sistemas de preparo do solo, foram de $0,0671,0,0409$ e0,0372 $\left(\mathrm{Mg} \mathrm{ha}^{-1}\right)\left(\mathrm{Mg} \mathrm{ha}^{-1}\right)^{-1}$, na média dos dois cultivos, com ampla variação de valores entre anos e culturas discutidos anteriormente.

Na cultura de milho, a eficácia relativa da SDI na redução da erosão hídrica, avaliada com base no fator $C$, foi de $44 \%$ em relação a $A+G$ e de $25 \%$ em relaçãoà $E+G$, na média dos dois cultivos, enquanto, na cultura de aveia, a referida eficácia foi de 45 e $9 \%$, concordando com dados de Margolis et al. (1985), DeMaria \& Lombardi Neto (1997) e Bertol et al. (2001). I sto é explicado principalmente pela presença dos resíduos vegetais na superfície do solo na SDI, os quais dissiparam a energia cinética das gotas de chuva e, ainda, pela diminuição de desagregação da superfície do solo em função da ausência de preparo nesse tratamento, em relação aos demais.

Os valores médios do fator $C$ foram maiores na cultura de milho do que na de aveia, em todos os sistemas de preparo do solo (Quadro 6). A maior variação entre culturas ocorreu na $E+G$ e, as menores, na SDI e E +G. Este comportamento é explicado pela erosi vidade das chuvas que, em média, foi $30 \%$ mai or no cultivo do milho do que no da aveia (Quadro 2), o que ocasionou maiores perdas de solo noSSC durante os ciclos do milho (Quadro 3) do que da aveia (Quadro 4) e, conseqüentemente, menores val ores deRPS no milho do que na aveia (Quadros 3, 4 e 5).

\section{CONCLUSÃO}

1. Os val ores médios de RPS para o mil ho foram de $0,1189,0,0888$ e 0,0611 ( $\left.\mathrm{Mg} \mathrm{ha}^{-1}\right)\left(\mathrm{Mg} \mathrm{ha}^{-1}\right)^{-1}$, para a aração+duas gradagens, escarificação+uma gradagem e semeadura direta, respectivamente, enquanto, para a aveia, foram, respectivamente, de 0,0783, 0,0655 e 0,0760 (Mg ha-1) (Mg ha-1 $)^{-1}$.

2. Os valores médios do fator $C$ para os respectivos preparos foram de 0,1097, 0,0809 e 0,0610 (Mg ha-1) $\left(\mathrm{Mg} \mathrm{ha}^{-1}\right)^{-1}$, no caso do milho, e de $0,0671,0,0409$ e 0,0372 ( $\left.\mathrm{Mg} \mathrm{ha}^{-1}\right)\left(\mathrm{Mg} \mathrm{ha}^{-1}\right)^{-1}$, no caso da aveia.

\section{LITERATURA CITADA}

BERTOL, I. Erosão hídrica em cambissolo húmico distrófico sob diferentes preparos do solo e rotação de culturas. R. Bras. Ci. Solo, 18:267-271, 1994.

BERTOL, I. \& ALMEIDA, J.A. Tolerância de perda de solo por erosão para os principais solos do Estado deSanta Catarina. R. Bras. Ci. Solo, 24:657-668, 2000.

BERTOL, I.; SCHICK, J . \& BATISTELA, O. Razão de perdas de solo e fator $C$ para as culturas de soja e trigo em três sistemas de preparo em um Cambissol o Húmico alumínico. R. Bras. Ci. Solo, 25:451-461, 2001.

CATANEO, A.; CASTRO FILHO, C. \& ACQUAROLE, R.M. Programa para cálculo deíndices de erosividade de chuvas. R. Bras. Ci. Solo, 6:236-239, 1982.

Quadro 6. Valores do fator C para cada ciclo das culturas de mi lho e aveia, obtidos pelo produto da razão de perdas de solo e fração do $\mathrm{EI}_{30}$, em três sistemas de manejo do Cambissolo Húmico alumínico em Lages (SC)

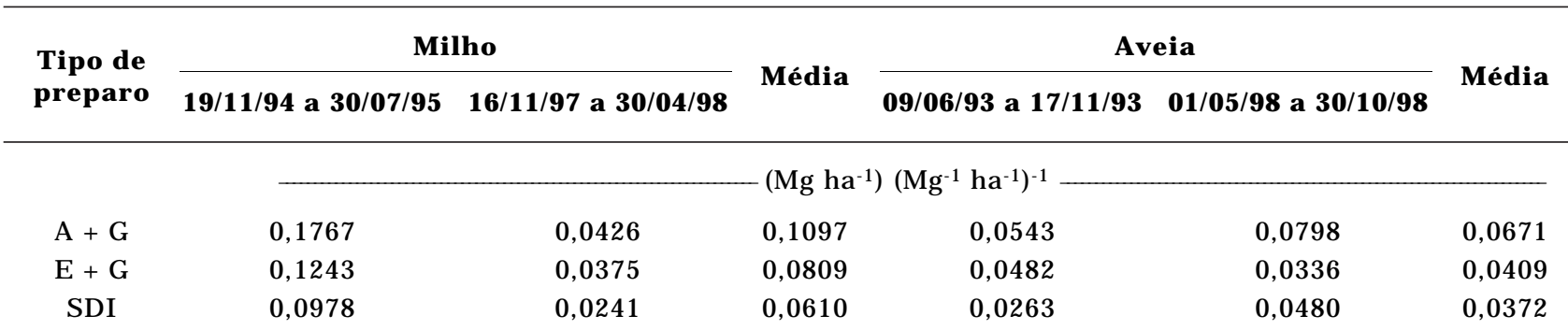

A + G: aração + duas gradagens; E + G: escarificação + uma gradagem; SDI : semeadura direta. 
COGO, N.P. Uma contribuição à metodologia de estudo das perdas de erosão em condições de chuva natural. I. Sugestões gerais, medição dos volumes, amostragem e quantificação de solo e água da enxurrada ( $1^{a}$ aproximação). In: ENCONTRO NACIONAL DE PESQUISA SOBRE CONSERVAÇÃO DO SOLO, 2., PaSSO Fundo, 1978. Anais. Passo Fundo, Empresa Brasileira de Pesquisa Agropecuária, 1978. p.75-98.

DEDECEK, R.A.; RESK, D.V.S. \& FREITAS J ÚNIOR, E. Perdas de solo, água e nutrientes por erosão em Latossolo Vermelho-escuro dos cerrados em diferentes cultivos sob chuva natural. R. Bras. Ci. Solo, 10:265-272, 1986.

DECHEN, S.C.F.; LOMBARDI NETO, F. \& CASTRO, O.M. Gramíneas el eguminosas e seus restos culturais no controle da erosão em Latossolo Roxo. R. Bras. Ci. Solo, 5:133-137, 1981.

DeMARIA, I.C. \& LOMBARDI NETO, F. Razão de perdas de sol o e fator $C$ para sistemas de manejo da cultura do milho. R. Bras. Ci. Solo, 21:263-270, 1997.

FOSTER， G.R.; MCCOOL，D.K.; RENARD， K.G. \& MOLDENHAUER, W.C. Conversion of the universal soil Ioss equation to SI metric units. J. Soil Water Conserv., 36:355-359, 1981.

HERNANI, L.C.; SALTON, J.C.; FABRÍCIO, A.C.; DEDECEK, R. \& ALVES J ÚNIOR, M. Perdas por erosão e rendimentos de soja e de trigo em diferentes sistemas de preparo de um Latossolo Roxo de Dourados (MS). R. Bras. Ci. Solo, 21:667-676, 1997.
LEVIEN, R.; COGO, N.P. \& ROCKENBACH, C.A. Erosão na cultura do milho em diferentes sistemas de cultivo anterior e métodos de preparo do solo. R. Bras. Ci. Solo, 14:73-80, 1990.

MARGOLIS, E.; SILVA, A.B. \& \& ACQUES, F.O. Determinação dos fatores da Equação Universal de Perdas de Solo para as condições de Caruaru (PE). R. Bras. Ci. Solo, 9:165169, 1985.

NASCIMENTO, P.C. \& LOMBARDI NETO, F. Razão de perdas de solo sob cultivo de três leguminosas. R. Bras. Ci. Solo, 23:121-125, 1999.

SCHICK, J .; BERTOL, I.; BATISTELA, O. \& BALBINOT J r., A.A. Erosão hídrica em cambissolo húmico alumínico submetido a diferentes sistemas de preparo e cultivo do solo - I: perdas de solo e água. R. Bras. Ci. Solo, 24:427436, 2000.

WISCHMEIER, W.H. A rainfall erosion index for a universal soil-loss equation. Soil Sci. Soc. Am. Proc., 23:246-249, 1959.

WISCHMEIER, W.H. Cropping-management factor for a universal soil-loss equation. Soil Sci. Soc. Am. Proc., 24:322-326, 1960

WISCHMEIER, W.H. \& SMITH, D.D. Predicting raifall erosion losses - a guide to conservation planning. Washington, USDA, 1978. 58p. (Agricultural Handbook, 537) 